\title{
COMMERCIAL PENICILLINS AND THE TREATMENT OF SYPHILIS : SOME RECENT AMERICAN DEVELOPMENTS
}

\author{
BY \\ R. R. WILLCOX \\ Lately Adviser in Venereology to the War Office
}

On Feb. 6 and 7, 1946, the United States Public Health Service convened a meeting of penicillin investigators of the National Research Council to set forth the latest developments in the treatment of syphilis with penicillin. (Willcox, 1946). Included in the data presented was that of the cumulative experience of the treating of over 11,500 cases of early syphilis. Much of the work which was described has since appeared in the American medical press, culminating with the issue of the Journal of the American Medical Association of May 25, 1946. This issue also contained a most important statement by the Committee of Medical Research of the United States Public Health Service and Food and Drug Administration (1946).

Within a week of that meeting, information came to light from two different laboratories (of Dr. Chesney and Dr. Mahoney, who were working on the value of the different fractions of penicillin in experimental syphilis) that relapses were occurring as often with 10 times the dose of penicillin $\mathrm{K}$ as with penicillin $\mathbf{G}$. Shortly after this, two widely separated clinics reported the paradoxical result that a schedule of a given dose over a given time was showing better results than another giving double the dose over double the time, the latter treatment having been done at a later date than the former. Enquiries then showed that commercial penicillin furnished originally in June, 1943, and for some months afterwards, had consisted predominantly of $G$; in 1944 , as a result of technicalities in its manufacture, it contained about equal parts of $\mathrm{G}, \mathrm{F}$, and $\mathrm{K}$; whereas in 1945, in that produced by some manufacturers, $\mathrm{K}$ was predominant.
Conference in March, 1946

In this unexpected state of turmoil it was decided to hold a further conference on penicillin in which were represented the United States Public Health Service, the Food and Drug Administration, and the National Research Council. The conference was held at the surprisingly early date of March 26 and 27, 1946, at Washington, D.C., and was attended by over 150 interested medical men. This meeting, as in the case of the former one, was presided over by Dr. J. E. Moore, and much extremely interesting material was presented.

\section{Experience of Research Workers}

The first speakers were research workers, who indicated their experience with the various penicillin fractions. Following the reports from Dr. Chesney and Dr. Mahoney, studies had been done on blood and urine assays of the various fractions in rabbits and in man. For these experiments all workers had been able to use crystalline $G$ and crystalline $X$ penicillins, and penicillins containing 90 per cent. of $K$ and 90 per cent. of $F$.

Dr. H. Eagle. (Johns Hopkins Hospital) said that in rabbits the blood levels produced by injections of $\mathrm{K}$ were markedly lower than those by the other penicillins, and similarly the concentrations produced were sustained over a shorter period of time. $\mathbf{X}$ gave higher levels than the others did, and for longer durations of time. Experiments on humans with $\mathbf{G}$ and $\mathbf{K}$ had shown a fourfold difference in the blood levels one hour after injection in favour of $G$, while the effect of $G$ persisted for double the time. If, as it might seem, $\mathbf{K}$ differed pharmacologically from the other three penicillins in that it was apparently destroyed 
in vivo (disappearing from the blood faster than the others and not being recoverable to the same degree in the urine), it could then be anticipated that it would be less active not only in syphilis but in any infection. It was estimated that against the streptococcus penicillin $\mathbf{K}$ was only one-seventeenth as active in vivo as it was estimated it would be in vitro, and therefore some better method of ascertaining therapeutic activity should be adopted than that of estimating the bactericidal potency in vitro. As penicillin $\mathrm{K}$ was relatively inactive from the pharmacological standpoint rather than from its lack of activity in vitro, there might be wide discrepancies in the unitage contents of ampoules of commercial penicillins when these were based upon in vitro assays.

Dr. Walsh McDermott (New York Hospital) had also made blood and urine assays on humans receiving the various fractions. He found that the penicillin concentrations in blood and urine following the administrations of crystalline $G$ were essentially the same as for the current commercial penicillins. Values for crystalline $\mathrm{X}$ were also the same when the staphylococcus was used as the test organism, but were significantly greater when the streptococcus were employed. K was markedly inefficient in producing a blood concentration, and, in contrast to all other penicillins, detectable amounts could not be found in the blood 1 hour after it had been given.

Dr. Coghill (Abbott Laboratories) had found that in humans there were significant levels of penicillin $G$ after 2 hours, where with $\mathrm{K}$ only one out of four showed detectable levels in 45 minutes. Work on urinary excretion showed that penicillin $G$ and penicillin $X$ were relatively stable in the body, whereas penicillin $\mathrm{K}$ was quite unstable and only a small amount remained long enough in the blood for it to be excreted. The current Abbott penicillin contained 92 per cent. $G$ and 8 per cent. $K$ and gave apparently the same results as for penicillin $G$. Mixing $G$ and $K$ with pooled sera from 8 subjects did not seem to indicate that anti-penicillin substances in the blood were responsible for the rapid disintegration of penicillin K.

Dr. Gladys Hobby (Charles Pfizer and Co.), who had been working on the relative values of the penicillin fractions, described results based on over 2,000 mouse-protection tests using a hæmolytic streptococcus. She considered from these tests that penicillin $\mathrm{X}$ was about half as effective as crystalline $\mathrm{G}$. The amount of $\mathrm{K}$ required was about twice that of $G$, because the former was eliminated from the blood stream extremely rapidly.

Dr. Justina Hill (Johns Hopkins University) presented data of in vitro work with the gonococcus which indicated that against this organism $\mathrm{X}$ was superior to $F$, and $F$ superior to $G ; G$ and $K$ were graded at about the same level of activity.

\section{Clinical Reports}

At this stage the meeting turned to the clinical side, and the chairman, Dr. J. E. Moore, summarized the events that had led up to the conference. He stated that, in view of what had occurred, the central statistical unit had analysed further some of the material presented at the February meeting in respect of the time factor and had found a significantly higher relapse rate in patients treated for syphilis after May, 1944, than in those treated before that date ; moreover, whereas the percentage becoming sero-negative at 11 months was 87 per cent. before that date, it had dropped to 62 per cent. afterwards.

Apart from the changes in the relative fractions in the penicillin already described, the potency of the penicillin obtained had varied from 220 units per mg. in 1943, to $900-1,200$ units per mg. in its current form; and, therefore, it was likely that impurities had been removed. It had already been suggested that these impurities might contain anti-spirochætal substances (Dunham and Rake, 1945). Information was not available about what proportions of penicillin fractions $\mathrm{G}, \mathrm{F}, \mathrm{X}$, and $\mathrm{K}$ were in the penicillins that had been employed in the treatment of syphilis, though batch samples were still held by the manufacturers and it might still be possible to determine such proportions. This, however, was not the only difficulty if the penicillin-syphilis data were to be adjusted, for it had also been discovered that the label dose of a bottle of penicillin signified its guaranteed minimum dose, and that there was no upper limit recorded of the maximum amount present.

Dr. Perrin Long (Johns Hopkins University) also emphasized that previous published work on penicillin was influenced by the knowledge now available that an ampoule of penicillin might contain anything between 97,000 and 140,000 units. Latterly a check on the results in pneumonia had also shown that double the dose was required to produce the same clinical effect as formerly.

\section{Chemical Aspects of the Problem}

At this stage, the meeting listened to the more chemical aspects of the problem, which it was hoped would show the way out from these sudden unexpected difficulties.

Dr. Hans Clark (Columbia University) discussed the formulæ and chemical properties of the various fractions, and said that one would expect that 
their affinity for water would increase from $K$ through $F$ and $G$ to $X$; while their affinity for lipids would decrease from $G$ through $F$ and $K$ to $\mathrm{X}$. It was possible that one or other of these solubility properties might have a determining influence on the selective action on different organisms.

Dr. F. F. Johnson (Cutter Laboratories) described an extraction method which caused a widely different distribution coefficient for each of the three penicillins $G, F$, and $K$, by means of which it was possible to separate three penicillins provided that it was known that only three antibiotics were present in the mixture. Dr. Lyman Craig then discussed the possibilities of the counter current distribution method as applied to the identification of the penicillin fractions. This involved the use of a separator machine, similar in principle to those used in the oil industry, but much simplified.

\section{General Discussion}

During the discussion that followed, the question of impurities was raised and Dr. Clowes (Eli Lilly and Co.) said it had been found that commercial penicillin would check the development of fertilized marine eggs but that the crystalline varieties would not do so. Even when the penicillins were removed the impurities still possessed this property. Dr. Eagle said that he had used many penicillins of different potencies, but as far as animal syphilis was concerned there was little to be said about any effect of the impurities.

Further general discussion indicated that there were probably only 4 penicillins in all ; that the respective amounts of the various fractions in commercial penicillins in the past 3 years were not known but probably could still be identified; that $\mathrm{X}$ was more stable than $G$ in the bottle; and that the use of precursors or adjuvants in the production could modify the amount of $G$ present and reduce that of $K$. If $K$ were present in the penicillin then the total number of units per mg. would be higher than without it. At this stage it became apparent that methods were known to the manufacturers which would increase the yield of the $G$ content, and that several manufacturers had already adopted them. Hence, there was some confusion as to why the clinical results had fallen off, for although $\mathrm{K}$ had been indicted, it appeared to be almost absent from the current penicillins. It was suggested that a time lag between discovery and performance was responsible for this. An advisory committee was set up to regulate further research in this important field, and the makers were being canvassed to find out what amounts of pure or nearly pure fractions they could make available for further study. It was then proposed and accepted by the meeting that it should be recommended that the grade of all penicillins should, as soon as possible, be labelled in milligrammes of penicillin and not in units.

\section{Events Subsequent to the Meeting}

After this meeting events moved with extreme rapidity. It was learnt by early July (Moore) that many of the difficulties of manufacture had already been overcome, that practically all the commercial penicillin in the U.S.A. consisted predominantly of $\mathrm{G}$, and that one firm had already placed on the market for commercial distribution a product containing 95 per cent. of $\mathrm{G}$. It was anticipated that similar action by others would soon follow. Meanwhile research schedules under public health service auspices had switched to crystalline $\mathbf{G}$.

Syphilis is one of the diseases in which, when studying the effects of penicillin, it is necessary to know with accuracy the dose that is being employed. Hithertofore we have misled ourselves into believing we had a gauge of that accuracy, and as a result most of the previously published work about the effect of penicillin on syphilis has been rendered invalid. An exact study can begin only when a pure or practically pure substance is being used. When it was hoped that this stage had been reached in the United States, that country was, in time, considerably in advance of us, though even so it was still unlikely that worthwhile information would be forthcoming for 18 months. Since then, however, rumours have been circulating on both sides of the Atlantic that perhaps these penicillin fractions are not themselves the pure substances they were at first thought to be, and that many of the difficulties so far encountered may possibly be experienced again. Should this happen, British manufacturers may have the opportunity of catching up or even exceeding those of the U.S.A. in 
furnishing a pure product for anti-syphilitic treatment.

Another aspect of the problem is whether it will be possible to find a penicillin selective for the gonococcus which will not at the same time mask an incubating syphilitic infection. It has already been shown that penicillin $\mathrm{X}$ is more effective for acute gonorrhoea than commercial penicillin, but that $\mathrm{X}$ is less effective than $G$ in causing the disappearance of treponemata from dark-field positive lesions. Preliminary tests, however, have not shown any indication that crystalline $X$ at any rate might not mask a syphilitic infection (Olansky and Putnam, 1946). Perhaps if further fractions are forthcoming this key, too, may be found.

\section{REFERENCES}

"Changing Character of Commercial Penicillin." Committee on Medical Research, United States Public Health Service and Food and Drug Administration (1946). J. Amer. med. Ass., 131, 271.

Dunham, W. B., and Rake, G. (1945). Amer. J. Syph., 29, 214.

Moore, J. E. (personal communication).

Olansky, S., and Putnam, L. E. (1946). J. vener. Inform., 27, 178.

Willcox, R. R. (1946). Nature, 158, 242. 